\title{
Research Paper: Determining Factors Affecting Fire Risk in a Hospital in Qazvin, Iran
}

\author{
Hazhir Kurd $^{1}$, Vida Zaroushanii ${ }^{2,3^{*}}$ (D), Yousof Akbari Shahrestanaki ${ }^{4}$ (D), Ali Safari Variani ${ }^{4}$
}

1. Student Research Committee, School of Public Health, Qazvin University of Medical Sciences, Tehran, Iran.

2. Department of Occupational Health, School of Public Health, Qazvin University of Medical Sciences, Qazvin, Iran.

3. Social Determinants of Health Research Center, Qazvin University of Medical Sciences, Qazvin Iran.

4. Department of Prehospital Medical Emergencies, School of Paramedical Sciences, Qazvin University of Medical Sciences, Qazvin, Iran

\begin{tabular}{l|l}
$\begin{array}{c}\text { Use your device to ocan } \\
\text { and read the article online }\end{array}$ \\
Qditation: Kurd H, Zaroushani V, Akbari Shahrestanaki Y, Safari Variani A. Determining Factors Affecting Fire Risk in a Hospital in \\
Qazvin, Iran. Health in Emergencies and Disasters Quarterly. 2021; 6(2):115-122. http://dx.doi.org/10.32598/hdq.6.2.370
\end{tabular}

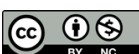

Article info:

Received: 06 Jun 2020

Accepted: 24 Nov 2020

Available Online: 01 Jan 2021

\section{Keywords:}

Risk assessment, Fire risk assessment method for engineering (FRAME), Fire, Hospital

\section{ABSTRACT}

Background: Hospitals are highly vulnerable to fire because of the presence of vulnerable people (patients, medical staff, and visitors), expensive equipment, and the ignorance and lowrisk perception of occupants. Injuries caused by fire can result in life and financial losses and can disrupt the performance of a hospital. Fire risk assessment is an effective way to assess vulnerability, capacity, and capability. This study aims to evaluate the risk of fire and identify the effective factors and their contribution to a hospital.

Materials and Methods: This cross-sectional study was conducted using the Fire Risk Assessment Method for Engineering (FRAME) in the equipment room of a hospital in Qazvin, Iran. The fire risk was first calculated by using the related formulas in Excel software. Then, the influential factors and their contribution to the overall risk were determined to perform corrective measures for reducing the risk.

Results: The numerical value of risk for the building and its contents, occupants, and activities were $2.075,3.315$, and 2.481 , respectively $(>1)$, indicating its unacceptable level. Factors affecting the potential risk level for the building and its content and occupants were fire load, venting, and access. Regarding the acceptable risk level, the activation factor was identified as an influential factor in all domains. The highest contribution in the potential risk level for the building and its content and occupants was related to the fire load factor (1.6). In the acceptable risk level, the highest contribution was related to the activation factor (0.4).

Conclusion: The FRAME method can also identify effective factors and their contribution to the overall fire risk of medical centers such as hospitals to help develop plans and special measures to reduce the risk.

\footnotetext{
* Corresponding Author:

Vida Zaroushani

Address: Department of Occupational Health, School of Public Health, Qazvin University of Medical Sciences, Qazvin, Iran

E-mail: v.zaroushani@qums.ac.ir
} 


\section{Introduction}

F

ire is defined as the rapid oxidation of materials at high temperatures with the production of heated gaseous products and the emission of visible and invisible radiation. Fires in residential and commercial buildings, hospitals, and small and large industries cause a great deal of human, financial, and environmental damage annually $[1,2]$. According to reports, half of the casualties due to fires occur in buildings [3]. Examination of past fires reveals that large fires usually occur for the first time without a tangible prognosis [4]. Among public buildings, health care facilities, especially hospitals, are undoubtedly the places that are often controlled by national laws and regulations. Given that the public believes that the government is responsible for caring for patients, hospitals' safety is becoming more critical and classified as sensitive and vital. According to data from the National Fire Protection Association (NFPA) survey in 2005, an average of more than 8000 fires occurs worldwide each year [5-7]. In hospitals, the use of renewable energy and flammable materials and the presence of hospitalized patients and those who refer to such places with physical and mobility limitations raise the need to pay serious attention to fire safety in these centers [8]. Since fire accidents in hospitals are usually associated with severe damage and mortality due to their relatively high vulnerability and low ability of residents [9], fire safety has become one of the biggest challenges facing designers and users [10].

National and international studies have been conducted to investigate the safety status of hospitals. In Mirzaei et al. study, hospitals in Ilam City, Iran, were reported to be at category B in terms of safety, indicating moderate resilience and the need for necessary measures in a short time to reduce the damages [11]. The safety level of hospitals affiliated to the Social Security Organization in Tehran in the Lari et al. study was in category C, indicating poor resilience and the need for immediate actions to protect the lives of patients and staff [12]. In examining the disaster preparedness of Virginia hospitals, Kimberley et al., suggested replacing existing equipment with higher-safety types [13]. The World Health Organization, in a report on the protection of hospitals in disasters, pointed out that, due to the presence of vulnerable and disabled people in hospitals and the provision of hospital services 24 hours a day on weekdays, these places are not quickly evacuated during accidents [14]. This issue shows the importance of hospitals as the main foundation of the health system in the risk response phase, which must be safe and resistant during accidents
[15]. The protection of human life and the human environment should be considered as a necessity in macronational and urban planning decisions [16].

Studies show that by implementing safety principles, $75 \%$ of fires can be predicted and prevented [17]. Choosing an appropriate fire safety engineering design is possible only after risk assessment [18]. The purpose of risk assessment is to evaluate the current situation and better understand the risks, leading to the classification and prioritization of identified risks [19]. The Fire Risk Assessment Method for Engineering (FRAME) is one of the most comprehensive, practical, and transparent computational methods for assessing fire risk in buildings [7], covering various aspects of fire such as building function, fire load, fire separation, and fire extinguishing systems. Using the FRAME method, the risk of the building can be objectively calculated [20]. FRAME was adapted from a method proposed by Swiss engineer Max Gretener in 1970 and developed by Eric De Smet. Mahdinia et al. assessed its validity for Iranian samples [21]. The validity of the FRAME method has been tested in real case studies in various ways, including consistency with the safety assessment results of some buildings performed by experts and the similarity of the influencing factors between FRAME and international fire regulations [22]. Other benefits of FRAME are the ability to be implemented in a short time, quantifiability of risk assessment, ability to evaluate the current status to assess the risk level before any remedial action to improve and estimate the amount of damage [23-25]. In Shirali et al. study, computational packages were prepared and calculated in Excel software for the risk of building and its equipment, residents, and activities separately in the control room of the power plant. Because of the high value of risks for residents, preventive measures were taken to reduce the level of risk using the FRAME method [26]. Sayyadi et al., in fire risk assessment of the hospital buildings in Kashan City, Iran, based on the FRAME method, found that the hospitals' fire risk level was high so that a fire could cause uncontrollable damages [7].

According to the 2001 Edition of NFPA Standard 805, fire fighting strategy should be based on the timely detection and extinguishing of fires, providing a specific degree of fire protection for the building, and fire prevention by systematic management of combustible materials and fire sources [19, 20]. By FRAME, analysis of the results obtained from the above factors can provide appropriate solutions to deal with fire in buildings or design of buildings under construction. Determination of the fire risk of power plants and implementation of control methods and preventive measures need financial costs. 
The identification of risk factors and their share in the overall risk can be beneficial to select these methods and measures and be considered as a weighted output in the FRAME method. The existence of multiple sources liable to catch fire or explode, as well as medical facilities often located in the sub-basement of the hospitals, make it highly vulnerable to fire. A fire in this area can have irreparable consequences for the whole building. Based on what was said, this study aims to evaluate the fire risk of a hospital building based on the FRAME method and determine the contribution of each risk factor to providing corrective solutions based on fire prevention principles.

\section{Materials and Methods}

This research is a descriptive cross-sectional study conducted in one of the hospitals in Qazvin City, Iran. We used the Persian FRAME method, whose validity was examined by Mahdinia et al. [17]. This method's main advantage lies in calculating the fire risk for three components: buildings and their contents, occupants, and activities. This method of fire risk assessment is for indoor places and is not applicable for outdoor places. The purpose of the FRAME is to assess the balance between the potential risk, protective measures, and probability of occurrence. The fire risk $(\mathrm{R})$ in this method is calculated as the quotient of the Potential Risk (P) by the Acceptance Level (A) and the Protection Level (D):

\section{1. $R=P /(A \times D)$}

The R-value less or equal to 1 indicates that the protective measures and risk acceptance levels are equal or greater than the potential risk level. Therefore, they are acceptable. While the R-value greater than 1 indicates that the potential risk is higher than the protection and acceptance levels. So the measures taken in the field of safety are not sufficient and, therefore, the risk is unacceptable, and the building requires intervention [23].

After getting acquainted with the different wards of the study hospital, fire risk for the three modes of building and its content, occupants, and indoor activities were assessed separately for the equipment room. This room is located in the sub-basement of the main hospital building and has an entrance from the main staircase of the floors and also an exit door to the outside. It is integrated with the main building, and all the cooling, heating, and electrical equipment of the hospital are located in this room. The data were collected based on observation, interviews, checking building's NFPA documents, and measurements. Then all the required formulas of the FRAME technique were written in an Excel sheet, and a sample solution was first performed to ensure the accuracy of the program. After obtaining numerical values, the formulas were re-checked to identify and correct possible errors. The final result of the calculations (R-value) is a number without a unit. Given that safety is relative, this number is always greater than zero (Figure 1).

To determine the influential factors and their contributions to the fire risk, the sub-parameters that increased the R-value above 1 were identified as effective factors. Their contribution level (weight) was obtained based on the R-value difference between the current and standard levels. According to Equation 1, if the score of each factor is equal to 1 , the $\mathrm{R}$-value will also be equal to 1 . If $\mathrm{P}$ $>1$ and $\mathrm{A}$ and $\mathrm{D}<1$, it shows that $\mathrm{R}$-value is greater than 1 and the safety is in a non-standard state (Figure 1).

\section{Results}

Based on the data available at the time of assessment, the fire risk scores for the hospital building and its content, occupants, and indoor activities in the equipment room were $\mathrm{R}=2.075, \mathrm{R} 1=3.135$, and $\mathrm{R} 2=2.481$, respectively (Table 1 ). Considering that all risk scores were $>1$ and according to the protective measures (Table 2), the building at all three modes had an unacceptable fire risk level. Given that the values of fire risk calculated in all three modes were in a range of 1.6 to 4.5 (Table 3 ), the use of fire detection and extinguishing systems such as sprinklers is essential for the equipment room. Moreover, considering a fire risk score of 3.135 for occupants, sufficient water supplies should also be provided for this room. Based on the calculated fire risk level for the building, the expected damage level to the building can be estimated based on Table 3. According to this table, the building's fire risk level (2.075) indicates that 80\%-100\% of the building will be destroyed in the event of a fire.

To identify the effective sub-parameters based on the $\mathrm{P}$ and $\mathrm{P} 1$ scores obtained from Equation 2 and 3, factors with a score higher than 1 were considered as effective factors:

$$
\begin{aligned}
& \text { 2. } P=q * i * g * e * v * z \\
& \text { 3. } P_{1}=q * i * e * v * z
\end{aligned}
$$

To identify effective sub-parameters based on the scores of A, A1, and A2 obtained from Equation 4, 5, 6 and considering that $A$ value $<1$ shows that the system is at risk, the sum of the values of a, t, c, r, d in Equation 3 must be less than 0.6; therefore, sub-parameters with a score $\geq 1$ were identified as influential factors. 


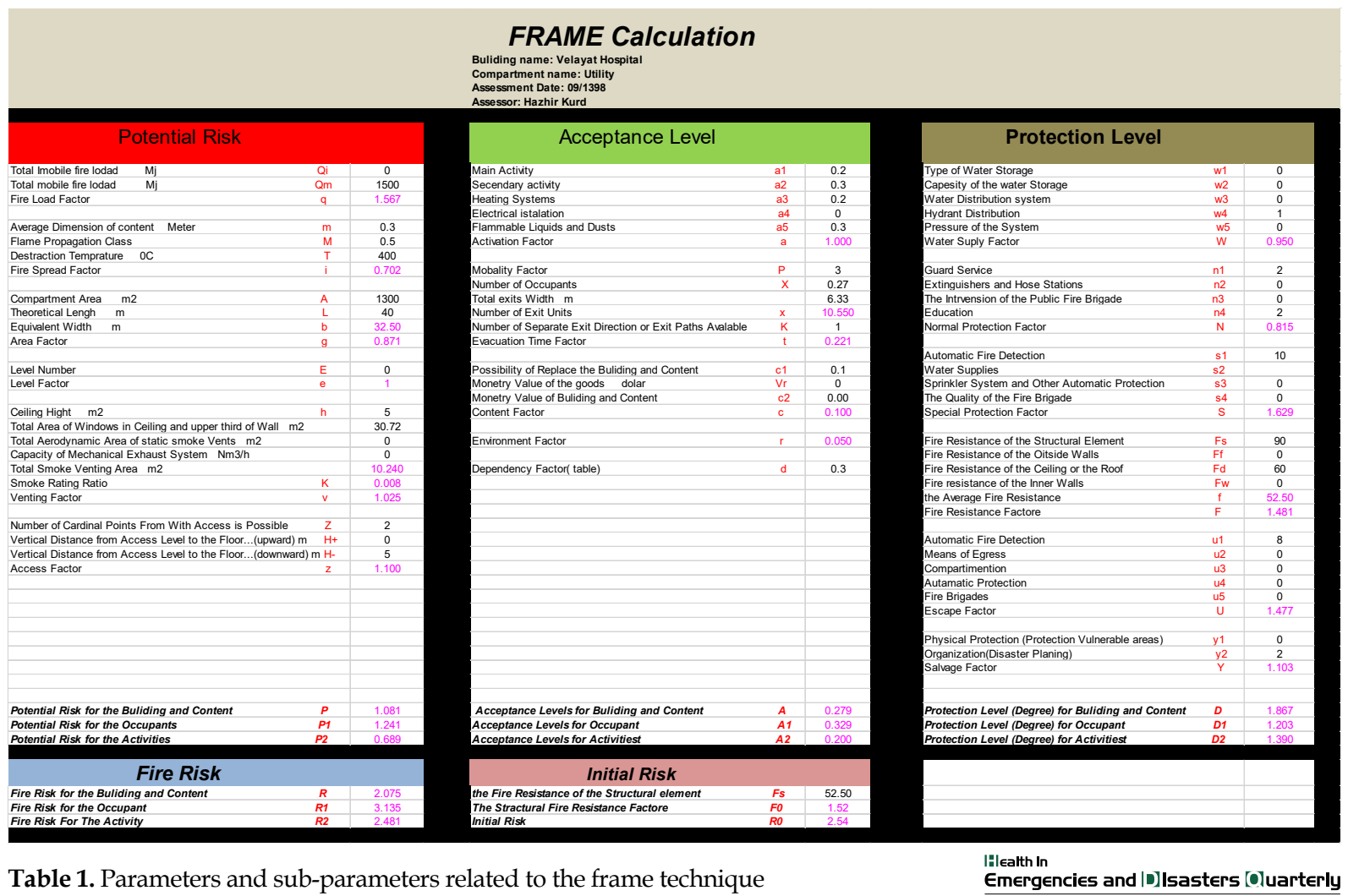

4. $A=1.6-a-t-r$

5. $A_{1}=1.6-a-t-r$

6. $A_{2}=1.6-a-c-d$

Results showed that the sub-parameters that lead to the increase in P and P1 values were common, including fire load factor, venting factor, and access factor. Regarding the A values (in all three modes), the activation factor was effective and common. Considering that performing preventive and corrective actions requires prioritization to select the best and most effective way, by examining the contribution rate, each parameter's role in the obtained number can be determined. The difference in the risk level (R) between the current state and the normal state represents the contribution of each sub-parameter (Table 4). As can be seen, the fire load factor had the

Table 1. The fire risk assessment results of the hospital

\begin{tabular}{|c|c|c|}
\hline Mode & Sub-parameter Value & Risk Value \\
\hline Building and its content & $P=1.081$ & \\
\hline Building and its content & $A=0.279$ & $R=2.075$ \\
\hline Building and its content & $D=1.867$ & \\
\hline Occupants & $\mathrm{P} 1=1.241$ & \\
\hline Occupants & $A 1=0.329$ & $R 1=3.315$ \\
\hline Occupants & $\mathrm{D} 1=1.203$ & \\
\hline Activities & $P 2=0.689$ & \\
\hline Activities & $A 2=0.200$ & $\mathrm{R} 2=2.481$ \\
\hline Activities & D3=1.390 & \\
\hline
\end{tabular}


Table 2. Proposed preventive measures based on the fire risk level

\begin{tabular}{|c|c|c|}
\hline \multicolumn{2}{|c|}{ Fire Safety Level } & \multirow{2}{*}{ 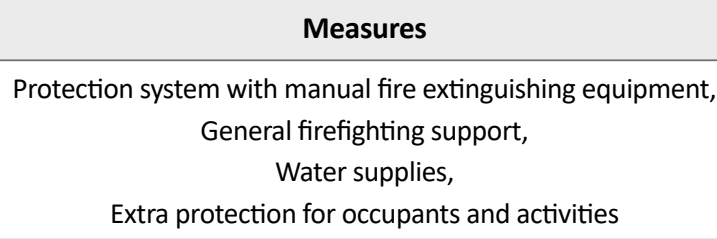 } \\
\hline $\mathrm{R}_{0}<1$ & Acceptable & \\
\hline $1-1.6$ & & $\begin{array}{l}\text { Automatic fire detection, } \\
\text { Water supplies, } \\
\text { Extra protection for occupants and activities }\end{array}$ \\
\hline $1.6-2.7$ & Unacceptable & Sprinkler system \\
\hline $4.5-2.7$ & & $\begin{array}{l}\text { Water supplies, } \\
\text { Extra protection for occupants and activities }\end{array}$ \\
\hline $\mathrm{R}_{0}>4.5$ & & Preventive measures to reduce the risk level \\
\hline
\end{tabular}

highest contribution to the obtained number of $\mathrm{P}$ and $\mathrm{P} 1$, followed by access and venting factors. Regarding A, $\mathrm{A} 1$, and A2 values, the activation factor had the highest contribution to the fire risk with a numerical value of 0.4 .

\section{Discussion}

This study was conducted using the FRAME method to assess fire risk in three domains of building and its content, occupants, and activities in the equipment room of one of the hospitals in Qazvin, Iran. Also, this study intended to identify influential risk factors and determining their contribution to fire risk. The factors that led to the harmful increase of $\mathrm{P}$ and $\mathrm{P} 1$ values were common, including fire load factor, venting factor, and access factor. Regarding the acceptable risk level (in all three domains), the influential factor was the activation factor. Fire load factor had the highest contribution to increasing the fire risk, followed by activation and access factors. In Shirali et al. study in 2014, fire risk for the occupants of a thermal power plant was at the highest level, followed by fire risk level for the building and its contents; both were at the unacceptable range according to the FRAME method. The reasons were the location of the control room at a level higher than the ground level and the impossibility of access to it for fire extinguishing, and the lack of an automatic fire alarm and extinguishing system [26]. In Aslani et al. study, the equipment and laundry rooms had the highest fire risk numbers due to their theoretical length, high area, and poor accessibility. Fire risk in all rooms in their study was unacceptable for occupants due to lack of attention to emergency exits, lack of fire detection and alarm facilities, and automatic fire extinguishing system. This finding is consistent with our results. The main reason is the presence of flammable materials, including flammable gases (urban gases) and liquids (diesel) required for boilers in the hospitals, although hospitals are in low-risk groups in terms of fire load and sources of ignition. By considering a separate space for

Table 3. The expected level of damage to the hospital building in the event of a fire

\begin{tabular}{|c|c|}
\hline Expected Damage Level (\%) & $\mathbf{R}$ \\
\hline$<10$ & Up to \\
\hline $10-20$ & $1-1.3$ \\
\hline $20-30$ & $1.3-1.5$ \\
\hline $30-50$ & $1.5-1$. \\
\hline $50-80$ & $1.7-1$. \\
\hline $80-100$ & $>1.9$ \\
\hline
\end{tabular}


Table 4. The contribution rate of influential fire risk factors

\begin{tabular}{|c|c|c|c|c|}
\hline Mode & Sub-parameter & Current State & Standard Level & Contribution Rate \\
\hline & Fire load factor & $P=1.567$ & $P=1$ & 0.567 \\
\hline \multirow[t]{2}{*}{ Potential risk for building and its content } & Venting factor & $P=1.025$ & $P=1$ & 0.025 \\
\hline & Access factor & $\mathrm{P}=1.100$ & $P=1$ & 0.1 \\
\hline \multirow[t]{2}{*}{ Acceptance level for building and its content } & Activation factor & $A=1$ & $A=0.6$ & 0.4 \\
\hline & Fire load factor & $P 1=1.57$ & $\mathrm{P} 1=1$ & 0.57 \\
\hline \multirow[t]{2}{*}{ Potential risk for occupants } & Venting factor & $P 1=1.025$ & $\mathrm{P} 1=1$ & 0.025 \\
\hline & Access factor & $P 1=1.10$ & $\mathrm{P} 1=1$ & 0.1 \\
\hline Acceptance level for occupants & Activation factor & $\mathrm{A} 1=1.00$ & $A 1=0.6$ & 0.4 \\
\hline Acceptance level for activities & Activation factor & $A 2=1.00$ & $A 2=0.6$ & 0.4 \\
\hline
\end{tabular}

diesel and emergency cutoff valves for the gas pipelines outside the equipment room, it is possible to reduce the amount of fire load contributing to the existing fire risk.

In Mahdinia et al. study (2012), the radiology wards and clinics of the study hospital had the highest fire risk for occupants. The influential factors were the location of the radiology ward in the sub-basement of the hospital, the movement of smoke upwards, and the problems in entering and exiting the radiology ward [21]. In the evaluation of a part of Hartford Nursing Center, the highest levels of risk for occupants were reported, whose main reasons were the high density of people and the high level of infrastructure without internal sub-division with cavity barriers [27]. In the Šakenaitè study, the fire risk of the building and its contents in the office building understudy was 0.61 , which was within an acceptable range due to low traffic and adequate infrastructure of the building [28]. In Sarsangi et al. and Mahdinia et al. studies, the level of building fire risk was within an unacceptable range for the pediatric ward of the study hospitals due to the impossibility of movement of children in the pediatric ward, non-consideration of building safety principles (including exit routes), lack of fire alarm and extinguishing system, and location of some wards in the upper floors [7, 21]. The fire risk of the building and the contents of the Hong Kong Airport was found to be acceptable in a study by $\mathrm{Ng}$ because of the installation of a sprinkler system in all areas and the observance of fire safety regulations during the construction of the airport building [29]. In this study, the fire risk level of activities according to the relevant formula in which the fire load factor and the moveable fire load were not involved was less than 1 and acceptable. This finding highlights the effect of fire load.

Fire load is divided into two categories of movable and fixed fire loads. Our results showed that in the equipment room, which was located on the sub-basement of the hospital building, the effect of fixed fire load was low, while movable fire load was very effective. Movable fire load is assessed according to the NFPA standard in relation to the amount of heat generated by the equipment and devices in the event of a fire in the area. Since the diesel stored in the corner of the equipment room and the gas pipelines for the boilers could be a great source of heat load generation, they were placed in the OH2 / NFPA OH GP2 category. Because of the high movable fire load and also considering the location of the study unit, in case of a fire, it can have irreparable consequences for other medical wards in the hospital. Its location must be changed so that possible accidents in this high-risk room do not threaten the safety and health of other sectors. A fire risk assessment was performed on the equipment and installations of Jam Hospital by Javidfar et al. showed that despite the high safety of the powerhouse, the fire risk was moderate.

For the safety of hospital facilities, equipment, and their safety are more critical, and venting factor is the most important criterion of facility fire. Regarding the venting factor, the three factors of movable fire load, ceiling height, and smoke venting ratio are influential. With an increase in the ceiling height, smoke layer thickness increases. The fire itself helps the smoke to find a way out. The presence of static and dynamic smoke ex- 
haust systems, as well as windows and smoke outlets in the upper third of the wall, reduces the risk of fire. There was no ventilation system in the study facility room, and the ratio of the existing area for smoke discharge to the area of the room was very low (0.008).

Moreover, the venting factor value was more than 1 . This means that the room fills with smoke in a short time. Experiments have shown that adequate ventilation can be provided if the smoke ventilation area is $1 \%-2 \%$ of the floor area. If the facility room area is $1300 \mathrm{~m}^{2}$, a ventilation area of $13-26 \mathrm{~m}^{2}$ is needed [27]. The area for the study facilities was $10.240 \mathrm{~m}^{2}$ and is necessary to be increased by at least 2-16 $\mathrm{m}^{2}$.

In our study, the movable fire load and venting factor were more effective in the fire risk. The Pareto principle applies to these factors. It means that many problems arise from a small number of factors, and by controlling them, the problem can be solved at a lower cost. The third factor that increased the potential fire risk for the building and occupants was the access factor which indicates limited access and problems of the fire brigade in accessing the fire level. Suppose firefighters have limited access to the fire, the access factor increases, which increases the potential risk for the fire. When comparing old buildings with no accessible space and new buildings with accessible space around them, the importance of the access factor becomes even more apparent. Building configuration is vital for fire fighting interventions. Access factors along with the area factor are essential elements in building configuration [27]. Therefore, the construction of new hospitals should be done in accessible locations so that access to the hospital from different geographical directions be possible and firefighters can intervene in emergencies.

One of the disadvantages of the software designed by Mehdinia et al. was the inability to select actions that significantly reduce the level of risk. So we suggested that in future studies, the possibility of adding an option to select effective parameters and their contribution rate be considered. It can help organizations in choosing more effective control methods. It is recommended that further studies be conducted to predict the likelihood of fire in the study room and simulate the consequences of this accident.

\section{Ethical Considerations}

\section{Compliance with ethical guidelines}

This study was approved by the Ethics Committee of Qazvin University of Medical Science (Code: 172148).

\section{Funding}

This study was extracted from the Master's thesis of the Hazhir Kourd and received support from Qazvin University of Medical Sciences.

\section{Authors' contributions}

All authors equally contributed to preparing this article.

\section{Conflict of interest}

The authors declared no conflict of interest.

\section{Acknowledgments}

This study was extracted from the Master's thesis of the first author (Ethic Code: 172148) and received support from Qazvin University of Medical Sciences. The authors would like to thank the Deputy for the Research of the university and the study hospital for their support and cooperation.

\section{References}

[1] Ahmadi S, Adl J, Varmazyar S. [Risk quantitative determination of fire and explosion in a process unit by Dow's fire and explosion index (Persian)]. Iran Occupational Health Journal. 2008; 5(1-2):39-46. Https://Www.Sid.Ir/En/Journal/Viewpaper.Aspx?Id=169722.

[2] Kobes M, Helsloot I, De Vries B, Post Jg. Building safety and human behaviour in fire: A literature review. Fire Safety Journal. 2010; 45(1):1-11. [DOI:10.1016/J.Firesaf.2009.08.005]

[3] Hirschler Mm. Fire hazard and fire risk assessment. United States: Astm International; 1992. Https://Books.Google. Com/Books?Id=Z8i2122glkyc\&Dq=Fire+Hazard + And +Fire + Risk+Assessment\&Lr=\&Source=Gbs_Navlinks_S

[4] Gholmohamadi R. [Fire engineering (Persian)]. Tehran: Mehrazan; 2005. https://www.gisoom.com/book/ 1643678 / \% DA \% A9\% D8\% AA \% D8 \% A7\% D8 \% A8-\%D9 $\% 85 \% \mathrm{D} 9 \% 87 \% \mathrm{D} 9 \% 86 \% \mathrm{D} 8 \% \mathrm{AF} \% \mathrm{D} 8 \% \mathrm{~B} 3 \% \mathrm{DB} \% 8 \mathrm{C}-$ \%D8\%AD\%D8\%B1\%DB\%8C\%D9\%82/

[5] Mahdinia M, Yarahmadi R, Jafari M, Koohpaie A, Khazaei M. [Fire Risk Assessment and the effect of emergency planning on risk reduction in a hospital (Persian)]. Qom University Of Medical Sciences Journal. 2011; 5(3):71-8. Http://Journal.Muq.Ac.Ir/Article-1-83-En.Html

[6] Hosseini SH, Seddighi A, Hosseini Amini H. [Pathology of mashhad hospitals with emphasis on passive defense case study: Razavi and Imam Reza hospitals (Persian)]. Geography. 2014; 12(42):211-38. https://www.sid.ir/en/Journal/ ViewPaper.aspx?:ID=420045 
[7] Sarsangi V, Saberi H, Malakutikhah M, Sadeghnia M, Rahimizadeh A, Aboee Mehrizi E. Analyzing the risk of fire in a hospital complex by "fire risk assessment method for engineering"(FRAME). International Archives of Health Sciences. 2014; 1(1):9-13. http:/ / eprints.hums.ac.ir/3562/

[8] Aslani A, Habibi E. [Evaluation of the risk of Fire by FRAME method and survey effect of sprinkler system existence, on the level of fire risk in the University hospital in 2016 (Persian)] Safety Promotion and Injury Prevention. 2019; 6(2):65-72. https://www.sid.ir/en/journal/ViewPaper.aspx?id=658705

[9] Lu S, Mei P, Wang J, Zhang H. Fatality and influence factors in high-casualty fires: A correspondence analysis. Safety Science. 2012; 50(4):1019-33. [DOI:10.1016/j.ssci.2011.12.006]

[10] Charters DA. Quantified assessment of hospital fire risks, interflam' 96. England: Cambridge; 1996.

[11] Mirzaee F, Kakaei H, Farasati F, Zamani N. [Investigating the safety and readiness of hospitals in Ilam against disasters in 2012 (Persian)]. Journal of Research, Ilam University of Medical Sciences. 2015; 22(7):14-23. http://sjimu.medilam. ac.ir/article-1-1711-fa.html

[12] Bahranifard A, Rahzani K, Maleki Rad AA, Malekpour M. Proposing an optimization procedure and applying management performance in health and medical emergency on preparedness of emergency department in suburb city hospitals. Preprints. 2017:2017080075. [DOI:10.20944/preprints201708.0075.v1]

[13] Cyganik KA. Disaster preparedness in virginia hospital center-arlington after Sept 11, 2001. Disaster Management \& Response. 2003; 1(3):80-6. [DOI:10.1016/S1540-2487(03)00048-8]

[14] Norozi MA, Jahangiri M, Ahmadinezhad P, Zare Derisi F. [Evaluation of the safety conditions of Shiraz University Of Medical Sciences educational hospitals using safety audit technique (Persian)]. Journal of Payavard Salamat. 2012; 6(1):42-51. http:/ / payavard.tums.ac.ir/article-1-44-en.html

[15] Azadian S, Shirali GA, Saki A. [Evaluation reliability and validity a questionnaire to assess crisis management based on seven principles of resilience engineering approach in hospitals (Persian)]. Iran Occupational Health. 2016; 13(1):15-26. http://ioh.iums.ac.ir/article-1-1244-en.html

[16] Hosseini AH, Asadi S, Bornafar M. [Evaluation of the structure Langrood city for passive defense planning (Persian)]. Journal Of Geographical Sciences. 2010; 15(18):129-49. https:// www.sid.ir/en/journal/ViewPaper.aspx?id=249908

[17] Yarahmadi R, Gholizade A, Jafari MJ, Kohpae A, Mahdinia M. [Performance assessment and analysis of national building codes with fire safety in all wards of a hospital (Persian)]. Iran Occupational Health. 2009; 6(1):28-36. https:/ / www.sid. ir/en/journal/ViewPaper.aspx?id=214225

[18] Jönsson R, Lundin J. The swedish case study, different fire safety design methods applied on a high rise building. LUTVDG/TVBB - 3099--SE. Department of Fire Safety Engineering and Systems Safety, Lund University. 1998; 3099. https:// lup.lub.lu.se/search/publication/605394

[19] Arghami SH, Boya M. [Industrial safety principles and services (Persian)]. Tehran: Fanavaran Press; 2005.

[20] Guo S. Fire risk assessment for commercial buildings based on FRAME method. International Conference on Ad- vanced Technologies in Energy, Environmental and Electrical Engineering (AT3E 2018) 26-28 October, Qingdao, China. IOP Conference Series: Earth and Environmental Science. 2019; 223: 012048. https://iopscience.iop.org/article/10.1088/1755-1315/223/1/012048/meta

[21] Mahdinia M, Yarahmadi R, Jafari M, Koohpaei A. [Presentation of a software method for use of risk assessment in building fire safety measure optimization (Persian)]. Iran Occupational Health. 2012; 9(1):9-16. http://ioh.iums.ac.ir/ article-1-704-en.htm

[22] Aslani AM, Habibi E. Evaluation of fire risk by FRAME method and study of the effect of crisis management team trained on fire risk level in Hazrat Rasool Akram Hospital (PBUH) in Fereydunshahr in2016 (Persian)]. Scientific Journal of Rescue and Relief. 2017; 9(1):46-55. https://www.sid.ir/ fa/journal/ViewPaper.aspx?ID=345266

[23] Smet ED. Theoretical basis and technical reference guide [Internet]. 2008 [Updated 2008]. Available from: http:/ / www. framemethod.net/indexen_html_files/FRAME2008TRG.pdf

[24] Taherzade Sh, Ziyaee M, Vafayi Nejad R, Akbari T. Assessing Mashhad hospital preparedness for disaster based on the HSI program. $8^{\text {th }}$ Asia Summit on Safe Society and the First Regional Summit of Safe Society in Mashhad, 2017. https:// civilica.com/doc/605701/

[25] Zarei E, Jafari M, Dormohammadi A, Sarsangi V. [The role of modeling and consequence evaluation in improving safety level of industrial hazardous installations: A case study: Hydrogen production unit (Persian)]. Iran Occupational Health 2013; 10(6):54-69. http://ioh.iums.ac.ir/article-1-878-en.html

[26] Shirali GA, Yarahmadi R, Kazemi E. [Determining the risk of fire by engineering approach and provide practical protection strategies in a thermal power plant (Persian)]. Iran Occupational Health. 2015; 12(5):75-82. http:/ / eprints.iums.ac.ir/4607/

[27] FRAME. FRAME fire risk evaluation method with Excel sheet application [Internet]. 2014 [Updated 2014 March]. Avilable from: http:/ / www.framemethod.net/

[28] Šakènaitè J. A comparison of methods used for fire safety evaluation. Mokslas-Lietuvos ateitis/Science-Future of Lithuania. 2010; 2(6):36-42. [DOI:10.3846/mla.2010.109]

[29] Ng M. Fire risk analysis of the airport terminals. International Journal on Engineering Performance-Based Fire Codes. 2003; 5(4):103-7. http://www.framemethod.net/indexen html_files/Hongkongairport.pdf 